\title{
Psychiatric Day Hospital and Its Impact on Patients Clinical Stability: The Reality of Faro (Portugal) Unit
}

\author{
Desidério Duarte*, Luís Ramos, Ana Cristina Trindade, Eduardo Gonçalves" \\ Department of Psychiatry and Mental Health (DPSM) of the Centro Hospitalar Universitário do Algarve (CHUA), Faro City, \\ Portugal \\ Email: *deduarte@chalgarve.min-saude.pt, "eduar.goncalves@gmail.com
}

How to cite this paper: Duarte, D., Ramos, L., Trindade, A.C. and Gonçalves, E. (2019) Psychiatric Day Hospital and Its Impact on Patients Clinical Stability: The Reality of Faro (Portugal) Unit. Open Journal of Psychiatry, 9, 15-22.

https://doi.org/10.4236/ojpsych.2019.91002

Received: December 10, 2018

Accepted: January 11, 2019

Published: January 15, 2019

Copyright $\odot 2019$ by author(s) and Scientific Research Publishing Inc. This work is licensed under the Creative Commons Attribution International License (CC BY 4.0).

http://creativecommons.org/licenses/by/4.0/

\begin{abstract}
Psychiatric Day Hospitals are alternatives to classic hospitalization, staying in an intermediate position between full-time hospitalization and outpatient treatment. The main purpose of this work was to investigate the impact of the therapeutic program developed in a Psychiatric Day Hospital (of Faro-Portugal) on the clinical stability of the patients. It is a descriptive-correlational retrospective study, implemented through the consultation of the SCLINIC computer platform regarding the years 2015, 2016 and 2017. The records of 127 users were analysed. There was a predominance of mood disorders $(n=55$; $43.3 \%$ ), followed by schizophrenia, schizotypal and delusional disorders ( $\mathrm{n}=$ 43, 33.9\%). The majority of patients had a structured occupational plan after discharge $(n=106,83.46 \%$ ). In the year following the frequency of Day Hospital, compared to the year prior to admission, there was a reduction in the number of full-time hospitalizations, outpatient visitations/consultations, prescribed drugs and emergency episodes, with statistically significant differences. The positive impact of the frequency of Day Hospital had on patients' clinical stability was the improvement in all studied variables. The Psychiatric Day Hospital of Faro-Portugal contributes to decreasing the number of full time hospitalizations, outpatient visitations/consultations and emergency episodes, maintaining patients' clinical stability and reducing the public financial costs related to their therapeutic intervention.
\end{abstract}

\section{Keywords}

Psychiatric Day Hospital, Therapeutic Program

\section{Introduction}

The concept of Psychiatric Day Hospital isn't new-the first experience of this 
kind arose in 1933, at the Psychiatric Hospital of Moscow [1]. It was exclusively designed for psychotic patients and their main purpose was the promotion of rehabilitation aiming the patients' entry into the labour market, to strengthen the productive performance during Stalin administration. The term "Day Hospital" only first appeared in 1946, through the initiative of Donald Cameron [1] [2]. This unit was inaugurated at the Memorial Institute of Psychiatry of the Allan MacGill University of Montreal. Initially it offered psychiatric treatments based on insulin shocks, group and individual psychotherapy and electroconvulsive therapy, but later became progressively more flexible to meet the individual needs of each patient [1] [3] [4] [5]. Psychiatric Day Hospitals reached an extraordinary evolution, spreading through Europe, United States and Canada. In less developed countries, they emerged as part of initiatives from professionals trained in these nations [1] [3] [4]. Several factors led to this phenomenon, which induced the replacement of asylum psychiatry model by the community care and socially inclusive pattern [1]:

- The increase of psychiatric illnesses in the Post World War II, associated with problems related to labour market adaptation;

- The entry of women into the labour force;

- The progressive transition from extended families to nuclear families making it difficult to support members who became ill;

- The recognition of psychotherapy as a form of extra-hospital treatment;

- The need of ensure the clinical stability of patients with fewer resources, aiming at reducing the overall cost of the disease.

At Portugal, in the late 1950s and early 1960s it became evident that the model of asylum psychiatry was manifestly insufficient. Several factors contributed to this change of mentalities [6]:

- The increasing industrialization and the creation of a stronger and more demanding working class;

- The increase in the prevalence of mental illness due to the Portuguese overseas war (Guinea-Bissau, Angola, Mozambique, India).

This led to the beginning of community psychiatry at Miguel Bombarda Lisbon psychiatric hospital, model which later spread to the rest of the country [6]. It was within this context that appears, in 1957, the first Day Hospital in Portugal, by the psychiatrist Barahona Fernandes, at Júlio de Matos Lisbon psychiatric hospital [7] [8]. Currently Psychiatric Day Hospital remains an alternative to classic hospitalization, staying in an intermediate position between full-time hospitalization and outpatient treatment [9]. It is defined by the Portuguese Central Administration of Health Systems (ACSS) as: "an organizational structure of a health institution with its own physical space, where qualified technical and human resources are provided, with scheduled care, for a period normally not exceeding 12 hours, not requiring overnight stay" [9]. It functions at the level of secondary prevention, offers psychotherapeutic treatments for a limited time, acts in crisis restraint and increases the quality of life of psychiatric pa- 
tients and their families. It aims the reduction of psychiatric symptoms, the relapse prevention, the cognitive improvement and the facilitation of family, social and labour integration, and the improvement of patients' social skills, contributing to the decreasing of the stigma related with mental illness [8]. Psychiatric disorders, according to the International Classification of Diseases (ICD-10), which mostly benefit from Day Hospital treatment are: schizophrenia, schizotypal and delusional disorders (ICD-10 code: F20-29); mood disorders (F30-39); neurotic, stress-related and somatoform disorders (F40-49); behavioural syndromes associated with physiological disturbances and physical factors (F50); disorders of personality and behaviour in adults (F60-69). The disorders for which there are no consensuses for the reference to Day Hospital are: organic, including symptomatic, mental disorders (F00-09); mental and behavioural disorders resulting from the use of psychoactive substance (F10-19); mental retardation (F70-79). Concerning Psychotic Disorders, Day Hospital is an important resource for increasing insight, avoiding social withdrawal, and increasing self-esteem. It also contributes to overcome the crises, restart the previous living standards and, if this is not possible, to find the most appropriate activity in order to avoid relapses. It is equally important for the patient to learn how to express emotions through verbal language, and improve therapy adherence [10]. Concerning personality disorders, Day Hospitals helps these patients, which are difficult to treat in outpatient setting, associated with a high consumption of resources in the emergency department and in outpatient clinics. Usually they are people with a low level of success in their attempts for family/social integration, particularly those with: traits of narcissistic, histrionic, borderline personality, which predispose to repeated situations of family/social conflict; phobic/avoidant personality; severe obsessive-compulsive symptomatology. Day Hospitals can act mainly in patients recovering from a hypo/manic phase or from a depressive condition, providing support to family/professional reintegration. Day Hospitals allow the treatment of more complicated eating behaviour disorders cases with supervision of the diet, without the necessity of full-time hospitalization [10]. In Faro city, in the south of Portugal, the Psychiatric Day Hospital was created in July 2008, at the Department of Psychiatry and Mental Health (DPSM) of the Centro Hospitalar Universitário do Algarve-Faro-Portugal (CHUA). Its intervention area covers nine counties of the Algarve: Albufeira, Loulé, Faro, São Brás de Alportel, Olhão, Tavira, Vila Real de Santo António, Castro Marim and Alcoutim. This unit provides care for patients over 18 years of age, with a maximum daily allowance of 20 patients, operates daily, closing on Saturdays, Sundays and holidays. The users' admission is mainly through the internment service (full-time hospitalization), the external consultation and the emergency unity of DPSM-CHUA. Within this research context it has been found a limited number of studies in this subject, which underlined the importance of carrying out this work. The data obtained will contribute to increase the knowledge in this subject, in order to improve the existing therapeutic program and the provided 
care.

\section{Methods}

The main objective of this work was the study of the impact of the therapeutic program developed at the Psychiatric Day Hospital of DPSM-CHUA on patient's clinical stability, defined by the amount of full-time hospitalizations, outpatient visitations (external psychiatric consultations), emergency episodes and prescribed psychotropic drugs. It has been hypothesized that this unit has a positive impact on patient's clinical stability. It is a retrospective observational, correlational study. For its implementation, a research was carried out on the SCLINIC computer platform, and analysed the data of all patients who frequented the Day Hospital during the years 2015, 2016 and 2017. The secondary purposes were the analysis of the clinical evolution of patients and the evaluation of the effectiveness of the therapeutic plan. The following variables were studied: socio-demographic data; clinical diagnosis; number of sessions attended at Day Hospital; referral after finishing the frequency of Day Hospital; number of full-time-hospitalizations, outpatient visitations/consultations, emergency episodes and prescribed psychotropic drugs during the year prior to entry into Day Hospital and during the year following discharge from this unit. The MannWhitney test was chosen, since two evaluations, through quantitative variables, were performed to the same patient's sample. This test is an alternative to t-test when there is no certainty about the normal/Gaussian character of the sample distribution and when their variance is equal. A significance level of $5 \%$ was used.

\section{Results}

It has been studied a sample integrating the totality of the patients $(n=127)$ attended in the Day Hospital during the 3 years. The safety of personnel and clinical data are guaranteed under the auspices of the Ethics Committee of the DPSM-CHUA, which previously authorized this statistical study. The patients were predominantly female (65\%), aged between 40 - 50 years old. Its distribution by municipalities is shown in Table 1.

Table 1. Patients attended in this Psychiatric Day Hospital.

\begin{tabular}{cc}
\hline Municipality & Number of patients \\
\hline Faro & $63(49.6 \%)$ \\
Loulé & $21(16.5 \%)$ \\
Albufeira & $19(15.0 \%)$ \\
Olhão & $11(8.7 \%)$ \\
Tavira & $9(7.1 \%)$ \\
São Brás de Alportel & $3(2.4 \%)$ \\
Vila Real de Santo António & $1(0.8 \%)$
\end{tabular}


These patients had diverse diagnosis with a predominance of mood disorders ( $\mathrm{n}=55,43.28 \%)$ and schizophrenia, schizotypal and delusional disorders $(\mathrm{n}=43$, $33.86 \%$ ). The distribution according to pathologies was as follows: F00-F09-Mental disorders due to known physiological conditions ( $\mathrm{n}=1 ; 0.78 \%)$. F10-F19-Mental and behavioural disorders due to psychoactive substance use ( $\mathrm{n}=3 ; 2.36 \%)$; F20-F29-Schizophrenia, schizotypal, delusional, and other non-mood psychotic disorders ( $\mathrm{n}=43 ; 33.86 \%)$; F30-F39-Mood (affective) disorders ( $\mathrm{n}=55 ; 43.28 \%$ ); F40-F48-Anxiety, dissociative, stress-related, somatoform and other nonpsychotic mental disorders $(\mathrm{n}=4 ; 3.14 \%)$; F60-F69-Disorders of adult personality and behaviour $(\mathrm{n}=21 ; 16.53 \%)$. A large variability was observed in the number of visits, with $25 \%$ of the patients needing more than 60 sessions, i.e., more than 3 months (standard treatment duration of this unit).Their ages were also quite variable, with the age group $40-49$ being the most representative $(n=40$, $31.5 \%$ ), followed by the group with $50-59$ years old ( $\mathrm{n}=31,24.4 \%), 20-29$ years old $(\mathrm{n}=23,18.1 \%), 30-39$ years old and $60-69$ years old (both with $\mathrm{n}=$ $16,12.6 \%)$ and finally by $70-79$ years old group $(n=1 ; 0.8 \%)$. The referrals after finishing the frequency of the Day Hospital program, were as follows: active professional life- $\mathrm{n}=53$ (41.73\%); without occupation- $\mathrm{n}=21$ (16.53\%); socio-occupational forum- $\mathrm{n}=19$ (14.96\%); training courses- $\mathrm{n}=17$ (13.38\%); senior university- $\mathrm{n}=5(3.93 \%)$; college/university- $\mathrm{n}=4(3.14 \%)$; full-time hospitalization- $\mathrm{n}=4(3.14 \%)$; other- $\mathrm{n}=4(3.14 \%)$. The data analysis of the year preceding the beginning of the therapeutic plan in this unit and the year after discharge showed that there were improvements at all analysed variables (Table 2). The frequency of Day Hospital allowed a great reduction in the number of hospitalizations in full-time psychiatric internment unit, in the drugs prescribed to each patient and in the emergencies episodes. The reduction of consultations/ outpatient visitations was less pronounced but equally statistically significant.

\section{Discussion}

Patients treated at the Hospital Day live mainly in the nearest towns of this unit, with residual presence in the more peripheral cities like Vila Real de Santo

Table 2. Amount of admissions in full-time psychiatric interment unit, psychiatric outpatient consultations, used psychotropic drugs and emergency episodes in the year before admission in the Day Hospital of DPSM-CHUA-Faro-Portugal (DH) and the year following the departure from this unit.

\begin{tabular}{cccccc}
\hline & \multicolumn{2}{c}{ Number } & \multicolumn{2}{c}{ Median (quartiles) } & \multirow{2}{*}{ p-value } \\
\cline { 2 - 5 } & Before DH & After DH & Before DH & After DH & \\
\hline Admissions & 130 & 26 & $1(0.0-2.0)$ & $0(0.0-0.0)$ & $1.3323^{-15^{*}}$ \\
Consultations & 393 & 277 & $3(1.0-4.0)$ & $2(1.0-3.0)$ & $0.0014^{*}$ \\
Psychotropic drugs & 546 & 445 & $4(3.0-5.5)$ & $3(3.0-5.0)$ & $0.0004^{*}$ \\
Emergency episodes & 278 & 94 & $2(1.0-2.0)$ & $0(0.0-1.0)$ & $8.8818^{-16^{*}}$ \\
\hline
\end{tabular}

${ }^{*} \mathrm{p}$-value from Mann-Whitney test (used to compare the medians). 
António, and nonexistent in the more distant ones, such Alcoutim. These data can be explained by the difficulty that exists in the accessibility of these patients, most of them holding socio-economic insufficiency (material deprivation) and precarious social situations. It would be important to have in mind that material support (transportation, for instances) must be available for everyone can have the same opportunities respecting the health services access, an issue that is expected to be corrected in the near future. The pathology distribution in this study is in accordance with the consulted bibliography, so individuals with psychotic, mood and personality disorders are the ones who benefit mostly with this therapeutic modality. After discharge from the Day Hospital, more than $40 \%$ of the patients returned to the workplace and/or attended professional courses. However, a considerable number of patients (16.53\%) remained unoccupied, which may be explained by the relatively advanced age of some patients and the cognitive deterioration presented by others, an important issue that should be considered in order to define strategies to overcome it. The positive impact that the frequency of Day Hospital had on the clinical stability of these individuals, with a reduction in the number of hospitalizations, psychiatric consultations, prescribed drugs and emergencies episodes, with statistically significant differences, translates, among other aspects, into less patient suffering, less cognitive deterioration and reduction of the treatment financial costs. These results are in concordance with the conclusions of the research studies carried out so far, although some presented apparently contradictory data, partially explained by the different methodologies and criteria. Lopes et al. (2012) reported that acute home care is not cheaper than Day Hospital, being this better than home care for patients with psychiatric conditions and it is related to a substantial reduction in hospitalizations [11]. Marshall et al. (2011) reported that there is no difference between the Psychiatric Day Hospital and the full-time internment, regarding the rehospitalisation rate [12]. Shek et al. (2009) reported that in the medium/long term (over one year), less persons allocated to Day Hospital care tend to be admitted to full-time internment hospital ( $\mathrm{n}=242$, relative risk, $\mathrm{RR}, 0.71$, confidence interval, CI, 56\% - 89\%) [13]. Kallert et al. (2007) reported that, compared to classic hospitalization, Day Hospitals are equally effective in terms of relief of the psychopathological symptoms, treatment satisfaction and quality of life, and more effective in social functioning improvement [14]. Marshall et al. (2001) reported that, compared with controls, subjects in Day Hospital spent significantly less hospital treatment days $(n=265,95 \% \mathrm{CI})$. In another study, it has been concluded that subjects in Day Hospitals showed a faster improvement in mental status than full-time hospitalized patients, however, there was no difference in readmission rates compared to control group $(\mathrm{n}=667, \mathrm{RR}=0.91$, 95\% CI) [15]. Psychiatric Day hospitals can be a valid alternative to classic hospitalization and home care, with advantages, not only economic but also, related to the improving user's quality of life. In this study should be considered some limitations, since it analyses data only from 3 years of operation of the Day Hos- 
pital of DPSM-CHUA-Faro-Portugal. Throughout its implementation, it was not possible to increase this range since the data prior to 2015 are not computerized and the information is widely dispersed, carrying on several gaps. In the future, with complete databases, this issue can be corrected and the inclusion of other variables, such as the degree of satisfaction with the treatment, the quality of life and the degree of psychopathology, will allow broader and more robust evaluation. This study is not representative of the general population.

\section{Concluding Remarks}

The main objective of this research study was to investigate the impact on clinical stability of the patients, of the therapeutic program developed at DPSMCHUA-Faro-Portugal Day Hospital. Analysis of the three-year data (2015-2017) confirmed the initial hypothesis that this unit has a positive impact on patient's clinical stability, contributing to reducing the number of full-time hospitalizations, psychiatric consultations, emergency episodes, and financial costs treatment. The impact of Psychiatric Day Hospitals is still a poorly studied subject, with a very limited number of research studies, which justifies larger investments in this area.

\section{Conflicts of Interest}

The authors report no conflicts of interest. There were no external sources of financing.

\section{References}

[1] Stagnaro, J.C. (2012) The Day Hospital: History and Conceptualization. VERTEX Revista Argentina de Psiquiatría, XXIII, 107-118.

[2] Charron, M. and Fraser, S.E. (2006) Cameron and the Allan Memorial Psychiatric Institute: A Study in Research and Treatment Ethics. In: Illuminati News. http://www.illuminati-news.com/ewen-cameron.htm

[3] Lima, M.P. and Botega N.J. (2001) Day Hospital: For Whom and for What? Revista Brasileira de Psiquiatria, 23, 195-199.

[4] Marshall, M. (2003) Acute Psychiatric Day Hospitals. BMJ, 327, 116-117. https://doi.org/10.1136/bmj.327.7407.116

[5] Vardaxi, C.C., Gonda, X. and Fountoulakis, K.N. (2018) Life Events in Schizoaffective Disorder: A Systematic Review. Journal of Affective Disorders, 227, 563-570. https://doi.org/10.1016/j.jad.2017.11.076

[6] Melo, M.S. and Ferreira, G. (1981) Community Psychiatry in the Historical Evolution of Psychiatry. Análise Psicológica, 3, 357-363.

[7] Fernandes, F.A. (2003) Psychiatry in History: Conde Ferreira Hospital and Psychopathology. Leituras, V, 54-61.

http://www.saude-mental.net/pdf/vol5_rev2_leituras.pdf

[8] Fonseca, V.C.R. (2011) Quality of Life and Psychopathology: Therapeutic Intervention in Day Hospital. In: Estudo Geral. https://estudogeral.sib.uc.pt/bitstream/10316/18425/1/Disserta\%C3\%A7\%C3\%A3o_ Vera\%20Fonseca.pdf 
[9] UONIE/ACSS (2010) Technical Recommendations for Day Hospital. RT04/2010. Ministério da Saúde. 1-2.

[10] Beorlegui, M.R.L., Hess, J.M., Amate, A.T., Baldomero, E.B., López, V.C., Cercós C.L., et al. (2000) Psychiatric Day Hospital Management Guide. In: Ministerio de Sanidad, Consumo y Bienestar Social.

http://www.ingesa.mscbs.gob.es/fr/estadEstudios/documPublica/psiquiatrico.htm

[11] Lopes, R. and Curral, R. (2012) Day Hospital in Community Psychiatry: Is It Still an Alternative to Mental Health Care? Arquivos de Medicina, 26, 218-223.

[12] Marshall, M., Crowther, R., Sledge, W.H., Rathbone, J. and Soares, K. (2011) Day Hospital versus Admission for Acute Psychiatric Disorders (Review). Cochrane Database of Systematic Reviews, No. 12. Art. No.: CD004026.

https://doi.org/10.1002/14651858.CD004026.pub2

[13] Shek, E., Stein, A.T., Shansis, F.M., Marshall, M., Crowther, R. and Tyrer, P. (2009) Day Hospital versus Outpatient Care for People with Schizophrenia. Cochrane Database of Systematic Reviews, Issue 4, Art. No.: CD003240. https://doi.org/10.1002/14651858.CD003240.pub2

[14] Kallert, T., Priebe, S., McCabe, R., Kiejna, A., Rymaszewska, J., Nawka, P., et al. (2007) Are Day Hospitals Effective for Acutely Ill Psychiatric Patients? A European Multicenter Randomized Controlled Trial. Journal of Clinical Psychiatry, 68, 278-287. https://doi.org/10.4088/JCP.v68n0214

[15] Marshall, M., Crowther, R., Almaraz-Serrano, A., Creed, F., Sledge, W., Kluiter, H., Roberts, C., Hill, E., Wiersma, D., Bond, G.R., Huxley, P. and Tyrer, P. (2001) Systematic Reviews of the Effectiveness of Day Care for People with Severe Mental Disorders: (1) Acute Day Hospital versus Admission; (2) Vocational Rehabilitation; (3) Day Hospital versus Outpatient Care. Health Technology Assessment, 5, 1-75. https://doi.org/10.3310/hta5210 